\title{
Implementation and evaluation of flipped learning for delivery of analytical chemistry topics
}

\author{
Fiona Ponikwer ${ }^{1} \cdot$ Bhavik Anil Patel $^{1}$ \\ Published online: 12 February 2018 \\ (C) Springer-Verlag GmbH Germany, part of Springer Nature 2018
}

\section{Introduction}

Traditional teaching methods are common in delivery of science, technology, engineering, and mathematics (STEM) subjects, where little active student participation is observed [1]. Active participation, such as answering questions or problem solving, often leads to more effective learning when compared with instructor-led lectures [2]. Moreover, a lack of active participation in the classroom regularly leads to a reduction in attendance and decreased engagement with the subject material.

Flipped learning, or the flipped classroom, is an innovative educational approach that has established itself in recent years as an alternative to traditional teaching methods. Most studies generally highlight the benefits of flipped learning, with the most significant being the ability to develop active learners [3-5]; however, others are sceptical, querying its efficacy in the lack of perceived gains in terms of grades [6] and resources needed to develop and deliver flipped learning [7].

There are many variants of the flipped classroom model, of which the most common use a blended learning approach, with study material being provided to the students in advance of the class to enable them to actively learn the subject area before the formal class time. Class time then establishes an interactive learning environment where students engage in activities and problem-based learning that are instructor led [5]. Flipped learning has been widely applied in STEM subjects, notably in the delivery of physics, engineering, and mathematics [3, 4, 8], and its use in chemistry teaching is increasing, with various studies being published on the delivery of organic or general chemistry in this way [8-16].

Bhavik Anil Patel

b.a.patel@brighton.ac.uk

1 School of Pharmacy and Biomolecular Sciences, University of Brighton, Huxley Building, Brighton BN2 4GJ, UK
There are, however, few studies on the implementation of flipped learning in analytical chemistry, which lends itself to this format of learning because of the problemsolving nature of the discipline [17-19]. One such study used Prezi-based presentations plus guided study to provide greater scope for focusing on complex problems within the classroom [18], concentrating predominately on the presentation platform students used, but producing limited insight into the effectiveness of the complete flipped model. Another study compared flipped learning's effectiveness for teaching both general and analytical chemistry, and found student attitudes were more positive towards flipped learning in analytical chemistry [17].

Our study focused on implementation and evaluation of flipped learning in a topic of analytical chemistry within a module taken by biomedical scientists over a period of 3 years. We compared the flipped learning approach with nonflipped lectures given within the same module. The flipped and non-flipped sessions were compared for engagement and performance.

\section{Study design}

The study was approved by the Ethics Committee of the School of Pharmacy and Biomolecular Sciences. The flipped learning approach was delivered in a first-semester fundamentals of analytical chemistry module to BSc honours degree biomedical science students. Figure 1 shows the study design used, where one third of the way through the traditionally taught module the lecturer used the flipped learning approach. Over the 3 years of the study, 290 students were exposed to flipped learning: during this time the average cohort age group, sex, and first-year higher education grade profiles were not significantly different between the years of study. Figure 1 also provides information on the topics that were delivered in the flipped and non-flipped learning approaches. 
Fig. 1 Study design for the delivery of flipped learning within the analytical chemistry module and the content and assessment covered in the flipped section
Semester module: Fundamentals of Analytical Chemistry

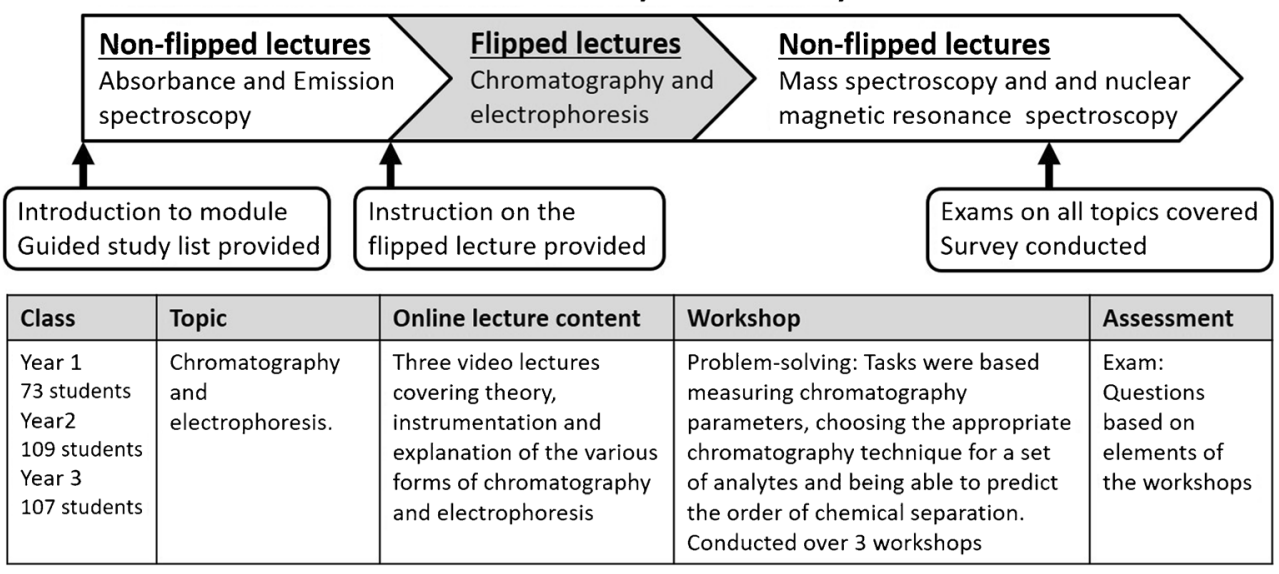

\section{Implementation and evaluation of flipped learning}

At the start of the module, students were informed about the content covered in the module, the assessment, and the guided study material they were required to complete to support their learning for all topics. The guided study materials were made available through the virtual learning environment (VLE) Blackboard®. Students were also informed there was a threshold attendance requirement of $80 \%$ if they needed to resit the assessment if they failed at the first attempt. Initially, students were given a series of conventional face-to-face lectures on the topic of absorbance and emission spectroscopy (6 h), then a flipped learning session on chromatography and electrophoresis $(6 \mathrm{~h})$, followed by a non-flipped teaching session on mass spectroscopy and nuclear magnetic resonance spectroscopy $(6 \mathrm{~h})$. At the end of the entire taught content, students were given a survey to complete (see Fig. 1).

For the non-flipped session, the classes consisted of lectures of $50 \mathrm{~min}$ which contained some examples of problems that were relevant to the examination. Students were also provided with a revision session to work through examples of unseen examination questions in the classroom. Students were notified about the flipped learning resources and how to access them 1 week before the delivery of the chromatography workshops. They were also told that they would be required - as guided independent study - to review the online material before the face-to-face problem-solving workshop class.

The self-study e-learning package was set up on the VLE, which consisted of video lectures created with Camtasia ${ }^{\circledR}$ and an online blog to allow students to post questions or flag up areas of difficulty. All students were encouraged to answer questions posted on the blog by their peers, with the lecturer moderating and providing responses, where necessary, for a fixed 2-h period each day. The video lectures were provided in approximately 30 -min segments for ease of access. This is generally longer than most suggested timescales for online video content; however, the timescales were appropriate for specific topics. The style of the video lectures was based on studies that provided insight into good video lecture construction [20,21]. All content within the VLE remained available for the duration of the module.

The first $15 \mathrm{~min}$ of the face-to-face problem-solving workshop was dedicated to any frequently occurring questions or topics highlighted in the online blog or sent by email. The remainder of the session was dedicated to a problem-solving activity as indicated in Fig. 1. The lecturer worked through one example of the activity with the whole class, after which the class, who were seated at tables consisting of eight to ten students, worked in smaller groups to conduct the activity (three or four students). The lecturer asked one student at the table who felt confident with the topic to act as a mentor for the table. This approach was similar to that adopted for the SCALE UP programme [22]. During the workshop sessions, the lecturer checked if each group had understood the material and facilitated learning with the aid of the student mentor.

Students were asked to provide constructive, evaluative feedback by completing an online survey provided at the end of the taught lectures and that was available up to the date of the module examination. The survey was designed with SurveyMonkey® with a mixture of questions eliciting Likert scale or free text responses. Data were also sourced from the VLE's learning analytics which showed how often and for what duration individuals accessed the material, as well as class registers, which allowed comparisons of attendance between the non-flipped and flipped lectures. Finally, examination grades were compared from topics taught by non-flipped and flipped learning within the module. 


\section{Student engagement with flipped learning}

To evaluate student engagement, we examined the number and duration of views of the online video lecture on chromatography theory, and attendance at its corresponding problemsolving workshop. Figure 2 shows the degree of engagement students had with this topic over the 3 years of this study. We also reviewed the number of views of this video lecture by students by the hour of the day over the same period (Fig. 2a). These significantly increased from 10 a.m. to 8 p.m. $(p<$ $0.05)$. This timeframe covered the 2 -h slot when students could post questions/issues on the online blog and received responses from the lecturer (Fig. 2a). This also suggests that students learn on timescales beyond the normal timetable and study during the evening. This may be explained by some students needing to work part-time to support their studies and having limited time for study during the normal working day.

The success of flipped learning is based on engagement with the online content before face-to-face contact. This is essential to make the 2-h problem-based workshops effective learning environments. Figure $2 \mathrm{~b}$ shows that students studied the online lecture material before the workshop, and this was consistent for all three years of this study. This indicates that the students were aware of the importance of the guided study and/or felt the pressure of being left behind when compared with peers who did engage with this learning approach. In one particular cohort (year 2), we observed a significant number of students who also engaged with the learning content after the problem-solving workshop, implying reflection on the content learnt.

When examining the average number of views per student over the 3 years for the chromatography theory video lecture content, we observed that most of the students looked at the content (Fig. 2c): only $4 \%$ of the students did not engage with the online videos. The median response was 13 views of the online video. The average time per view of the chromatography theory video lecture was $13 \pm 4 \min (n=278)$. This viewing time is similar to what is indicated for an appropriate time for video content online [23]. There was no significant difference in the number of views and the average time per view for all the other video lectures provided as part of the flipped learning study. As the online lecture content (approximately $30 \mathrm{~min}$ in duration) was required to be reviewed before the lecture, it is most likely that most students watched the entire online material in very short bursts before they attended workshop. This suggests that the students are engaged with the flipped learning model and have actively participated in their learning, as they are reviewing the online material. The fact that they engage with the material in multiple bursts of brief timescales suggests a preference to learn material in small packages, which, as suggested by Abeysekera and Dawson [24], would reduce and spread cognitive load and provide time for reflection.
Figure $2 \mathrm{~d}$ shows the differences in the attendance at the flipped and non-flipped classes. There was no significant difference in the attendance at the start of the module and the flipped session; however, there was a significant reduction in the attendance at the non-flipped lectures delivered after the flipped sessions ( $p<0.05, n=3$ ). Although not significant, there was a slight increase in the attendance during the flipped learning session when compared with when the module started. This change in attendance may be due to increased engagement in the flipped learning module; however, it could also reflect a perception that a more exciting approach of lecturing or content is to be delivered. The enhanced level of engagement may also be because students could feel left behind in the problem-solving workshop sessions. The reduction in attendance after the flipped lecture may be due to students deciding to focus on assessments, feeling that they may have met the threshold attendance requirement.

\section{Usefulness of and satisfaction with the flipped learning model}

We received 81 survey responses from the 290 students (28\%) who studied the module over 3 years. Figure 3 a shows the relative usefulness of each of the delivery aids used for flipped learning. We used a Likert scale system, where 5 corresponded to the most useful activity to aid their learning of the topic. For the online blog, the mean response was 3.08 [95\% confidence interval $(\mathrm{Cl}) 2.87-3.29, n=64]$. For the online video lectures, the mean score was $4.15(95 \% \mathrm{Cl}$ $3.91-4.39, n=61)$. For the face-to-face problem-solving workshops, the mean score was $4.51(95 \% \mathrm{Cl} 4.36-4.65, n$ $=73$ ). Students found the taught problem-solving activities in the workshops to be more useful than the online blog $(p<$ $0.001, n=64-73$, Tukey test) and the video lectures $(p<$ $0.05, n=61-73)$. From the electronic components available, students found the online video lectures to be more useful than the blog $(p<0.001, n=61-64)$. These findings are as expected, as the problem-solving workshops engage students in activities which are regularly seen to be more stimulating than conventional lectures [25]. There is often less time to conduct problem-solving learning activities in analytical chemistry classes as classroom time is dominated by the need to ensure the students understand the underlying theory. The online lectures were also deemed to be highly successful, possibly because they were short, and allowed students to learn at their own pace.

The online blog split opinion, with half of the students enjoying it and the other half disliking it. There are two factors which probably account for this. Firstly, students want an immediate response to a blog entry, which cannot be easily offered because of them posting blog entries at different times. Secondly, many students were not keen for their peers to see 
Fig. 2 Engagement with flipped learning content for material on chromatography theory. a Number of views per hour of the day, $\mathbf{b}$ number of views per day of the week, $\mathbf{c}$ number of views per student for one online video before the taught workshop over 3 years, and $\mathbf{d}$ changes in attendance at flipped and nonflipped sessions

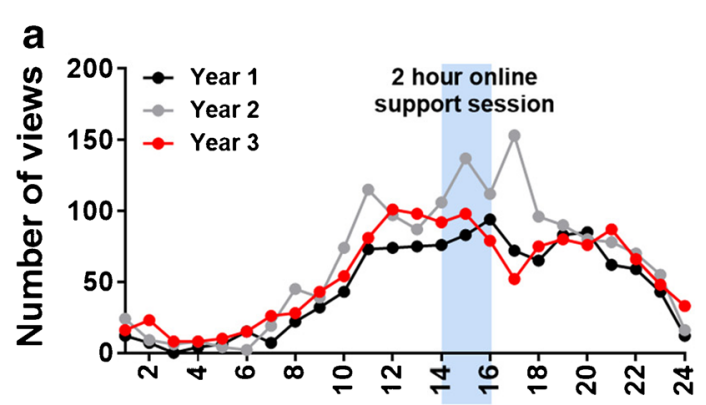

Hour of day

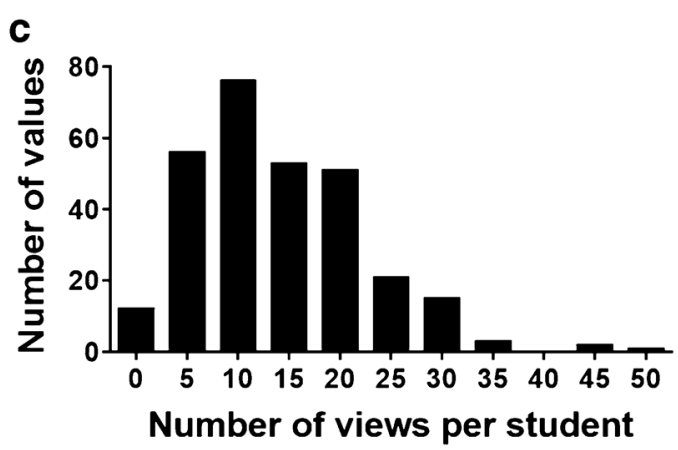

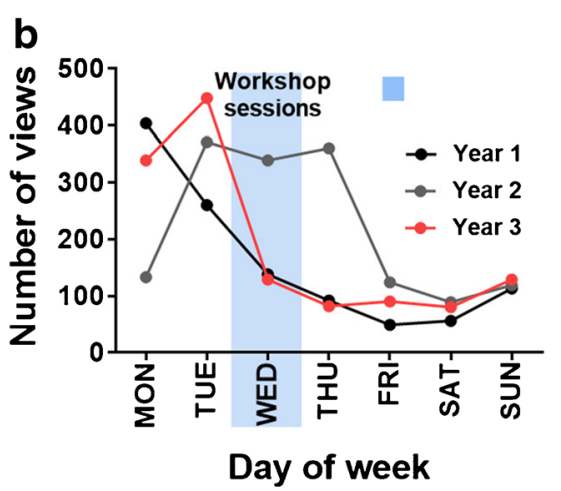

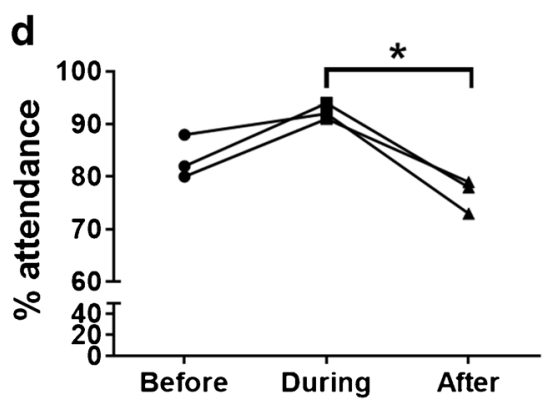

their posted questions, and therefore they e-mailed the lecturer with regard to areas of concern they would like to have covered in class. During the flipped learning activity, the staff member received 45 e-mails. This further highlighted that students were interested in directing their own learning.
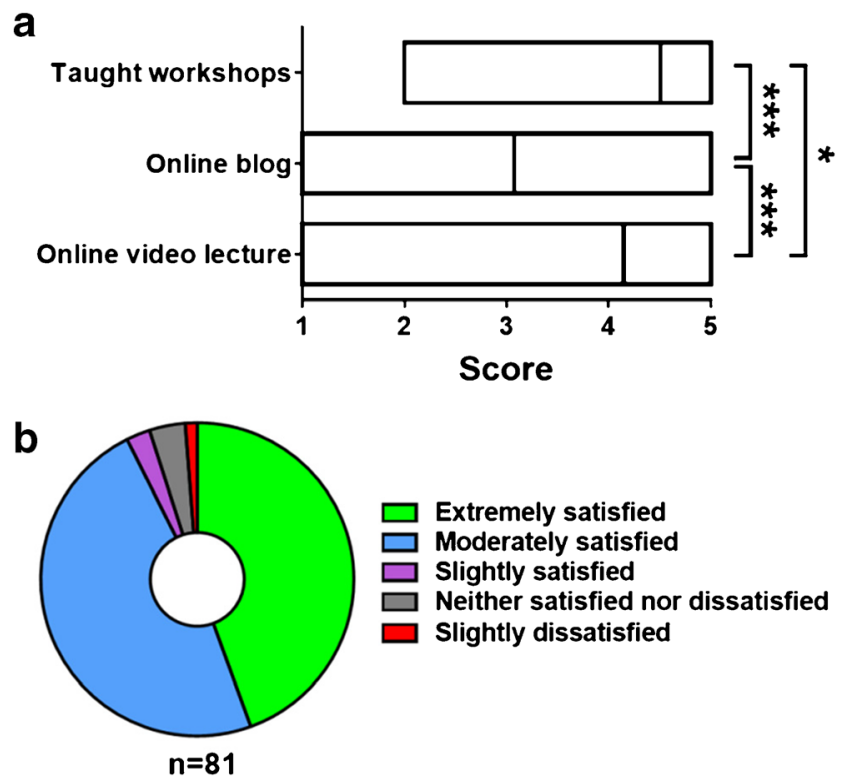

Fig. 3 Usefulness of (a) and satisfaction with (b) the activities used for delivery of flipped learning. Usefulness was monitored with a Likert scoring scale, where 1 was considered not useful and 5 was considered extremely useful. Data shown as mean \pm range, where $* p<0.05$ and $* * * p<0.001$.
Figure $3 \mathrm{~b}$ shows the students' degree of satisfaction with the flipped learning approach for delivery of analytical chemistry when compared with conventional lectures. We found that $95 \%$ of the students were satisfied to some degree with this format of learning. This suggests that flipped learning can be an effective educational approach for delivery of analytical chemistry as shown for other areas of chemistry $[5,8]$.

\section{Student perception of flipped learning}

Table 1 shows show the students' perceived strengths of flipped learning. The major recurring comments from students were that video lectures can be reviewed many times (particularly mentioned by international students), and that they could check/practise their understanding and knowledge of the learnt video material with the lecturer in the taught problem-based workshop. Other key comments are all indicative that this approach to teaching makes students engage more actively in the learning process.

Table 2 shows what students perceived as weaknesses in using flipped learning to deliver analytical chemistry. In comparison with the strengths, fewer weaknesses were raised by the students. The key issues are associated with students who failed to understand aspects of the online materials and how this can make it hard to understand the problem-based workshop. Other issues were all focused and associated with students having to put in more effort and be more motivated to learn the study materials independently. This aspect meant that 
Table 1 The perceived strengths of flipped learning for delivery of analytical chemistry
Comments mentioned

Count

\begin{tabular}{lc}
\hline Can review as many times as desired (international students particularly liked this) & 16 \\
Learn at own pace/personalized method & 6 \\
Can check understanding/practise material with lecturer & 23 \\
Provides a deep understanding of material & 9 \\
Encourages more reading outside face-to-face time & 3 \\
Learnt more as had to apply the knowledge & 8 \\
Take in far more than when just listening to a lecture & 4 \\
Gives me more confidence in applying the principles in real-life scenarios & 1 \\
Encourages you to read outside lectures as you will be tested on knowledge in the next lecture, which is & 6 \\
beneficial to other subjects as well & \\
Easier to go through the material and write your own notes & 7 \\
The student is more in control; not taught at, or spoon-fed the content of the lecture & 4 \\
Problem-based workshops provide a forum for debate to chew over the applications & 8
\end{tabular}

students also found this style of learning forced them to take ownership of their time management, and some found this particularly challenging.

Another limitation of flipped learning is that students are unable to have any aspects of the video lecture clarified as they watch it in their own time. In this study, we tried to overcome this issue by using a fixed time slot for interaction with the online blog and dedicating the first $15 \mathrm{~min}$ of each workshop to cover any material students flagged as difficult by e-mail and/or by the blog.

\section{Enhancement of performance}

In the module assessment, students are required to answer two questions from three options on the examination paper. Two questions in the examination were from topics covered by conventional lecturing and one question was taught with the flipped model. Comparisons were obtained only where students had answered one question covered by the flipped approach and one question taught by conventional lectures. Over the duration of 3 years, the average grade out of 20 marks for the flipped taught content was $12.6 \pm 4.2$, which significantly reduced to $9.4 \pm 5.8(p<0.001$, Student's $t$ test, $n=213)$ for the non-flipped taught content. This suggests there was an average $16 \%$ increase in the marks for the content delivered by flipped teaching. This improved performance could be due to the flipped learning approach enhancing student learning, but may also be due to other factors, such as students finding the topic of chromatography more interesting or easier than spectroscopy, or that the format of flipped learning made students feel more positive about the subject area compared with those subject areas that were delivered traditionally.

\section{Benefits of using flipped learning for delivery of analytical chemistry}

There is no doubt about the effectiveness of flipped learning in education of general and organic chemistry [8, 10, 13-16]. What is less evident, as there are only a few studies $[17,18]$, is if analytical chemistry is well suited to the flipped teaching
Table 2 The perceived weaknesses of flipped learning for delivery of analytical chemistry topics

\begin{tabular}{lc}
\hline Comments mentioned & Count \\
\hline Need to be organized & 3 \\
If others don't do work in advance, it slows the whole class & 5 \\
If online material is not understood, it can be hard to follow the class exercises efficiently & 12 \\
Time-consuming & 3 \\
Self-motivation is lacking to watch material outside class & 6 \\
I don't learn this way & 3 \\
Audio quality is poor in places & 2 \\
More work to do in our spare time & 6 \\
Coming to lectures is pointless & 2
\end{tabular}


model. This study suggests that flipped learning can be an effective model for teaching analytical chemistry in single topics and potentially entire modules. This approach provides the means for students to take active responsibility in their learning, which they can do at their own pace, and to conduct problem-solving activities within the classroom environment, which underpins the discipline of analytical chemistry.

\section{Conclusions}

Analytical chemistry is a discipline that is focused around problem solving and therefore is ideally suited to flipped learning. We have successfully implemented and evaluated the effectiveness of flipped learning for the delivery of analytical chemistry content. There was high engagement with all the flipped learning resources except the online blog. Our metric-based data suggest that $96 \%$ of students would have studied the online video lectures for sufficient duration to actively learn the content. Students highlighted that the online video lecture provided flexibility in when they can learn the material, and at a pace to suit their individual learning needs, which spreads and reduces cognitive load. The students found the problem-based workshops the most useful element, because of the interactivity in the classroom environment, but they were not so keen on the online blog as a means of asking questions on aspects of the electronic lecture they did not fully understand. The students were satisfied with the flipped learning when compared with conventional lecturing. Therefore, flipped teaching can be used for the entire course. Overall, these findings suggest that students took active responsibility for their learning and were satisfied with being able to learn at their own pace and conduct problem-based activities in classroom sessions. The combination of such activities provides a means to spread cognitive load when learning a topic and increasing germane load-based activities associated with that learning, which provides in-depth understanding.

\section{Compliance with ethical standards}

Conflict of interest The authors declare that they have no competing interests.

\section{References}

1. Cooper JL, Robinson P. The argument for making large classes seem small. New Dir Teach Learn. 2000, 2000;(81):5-16.

2. Mayer RE, Stull A, DeLeeuw K, Almeroth K, Bimber B, Chun D, et al. Clickers in college classrooms: Fostering learning with questioning methods in large lecture classes. Contemp Educ Psychol. 2009;34(1):51-7.
3. Covill D, Patel B, Singh GD. Flipping the classroom to support learning: an overview of flipped classes from science, engineering and product design. Sch Sci Rev. 2013;95(350):73-80.

4. O'Flaherty J, Phillips C. The use of flipped classrooms in higher education: a scoping review. Internet High Educ. 2015;25:85-95.

5. Seery MK. Flipped learning in higher education chemistry: emerging trends and potential directions. Chem Educ Res Pract. 2015;16(4):758-68.

6. McLaughlin JEPMS, Griffin LMP, Esserman DAP, Davidson CAME, Glatt DM, Roth MTP, et al. Pharmacy student engagement, performance, and perception in a flipped satellite classroom. Am J Pharm Educ. 2013;77(9):196.

7. Vogel L. Educators propose "flipping" medical training. CMAJ. 2012;184(12):625-6.

8. Flynn AB. Structure and evaluation of flipped chemistry courses: organic \& spectroscopy, large and small, first to third year, English and French. Chem Educ Res Pract. 2015;16(2):198-211.

9. Christiansen MA. Inverted teaching: applying a new pedagogy to a university organic chemistry class. J Chem Educ. 2014;91(11):1845-50.

10. Fautch JM. The flipped classroom for teaching organic chemistry in small classes: is it effective? Chem Educ Res Pract. 2015;16(1):179-86.

11. Rein KS, Brookes DT. Student response to a partial inversion of an organic chemistry course for non-chemistry majors. J Chem Educ. 2015;92(5):797-802.

12. Eichler JF, Peeples J. Flipped classroom modules for large enrollment general chemistry courses: a low barrier approach to increase active learning and improve student grades. Chem Educ Res Pract. 2016;17(1):197-208

13. Robert J, Lewis SE, Oueini R, Mapugay A. Coordinated implementation and evaluation of flipped classes and peer-led team learning in general chemistry. J Chem Educ. 2016;93(12):1993-8.

14. Ryan MD, Reid SA. Impact of the flipped classroom on student performance and retention: a parallel controlled study in general chemistry. J Chem Educ. 2016;93(1):13-23.

15. Shattuck JC. A parallel controlled study of the effectiveness of a partially flipped organic chemistry course on student performance, perceptions, and course completion. J Chem Educ. 2016;93(12): 1984-92.

16. Weaver GC, Sturtevant HG. Design, implementation, and evaluation of a flipped format general chemistry course. J Chem Educ. 2015;92(9):1437-48.

17. Esson JM. Flipping general and analytical chemistry at a primarily undergraduate institution. ACS Symp Ser. 2016;1228:107-25.

18. Fitzgerald N, Li L. Using presentation software to flip an undergraduate analytical chemistry course. J Chem Educ. 2015;92(9): 1559-63.

19. Harrison C. Flipping the analytical chemistry classroom. The Analytical Scientist. 2014;17:20-6.

20. Smith CM, McDonald K. The flipped classroom for professional development: part II. making podcasts and videos. J Contin Educ Nurs. 2013;44(11):486-7.

21. Raths D. Nine video tips for a better flipped classroom. Educ Dig. 2014;79(6):15.

22. Gaffney JD, Richards E, Kustusch MB, Ding L, Beichner RJ. Scaling up education reform. J Coll Sci Teach. 2008;37(5):48.

23. Guo PJ, Kim J, Rubin R. How video production affects student engagement: an empirical study of MOOC videos. In: Proceedings of the first ACM conference on learning @ scale conference. 2014. New York: Association for Computing Machinery; 2014. p. 41-50.

24. Abeysekera L, Dawson P. Motivation and cognitive load in the flipped classroom: definition, rationale and a call for research. High Educ Res Dev. 2015;34(1):1-14.

25. Freeman S, Eddy SL, McDonough M, Smith MK, Okoroafor N, Jordt $\mathrm{H}$, et al. Active learning increases student performance in science, engineering, and mathematics. Proc Natl Acad Sci U S A. 2014;111(23):8410-5. 


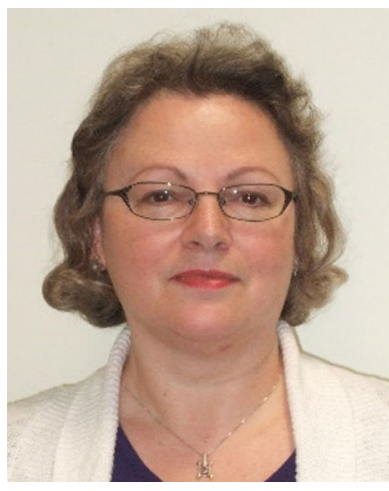

cation and transitions into different levels of HE.
Fiona Ponikwer is Lecturer in Learning \& Teaching Quality and Academic Support Tutor in the School of Pharmacy \& Biomolecular Sciences at the University of Brighton. She is involved in teaching study skills and research methods to students from foundation year to Masters Level, and is a keen proponent of student engagement in the classroom. Her research interests include professional development of science students, interprofessional edu-

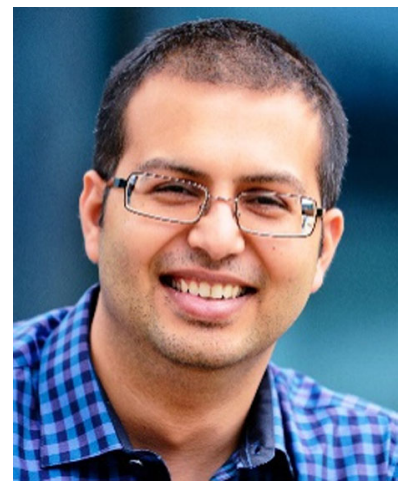

Bhavik Anil Patel currently is a Reader in Clinical and Bioanalytical Chemistry in the School of Pharmacy and Biomolecular Sciences at the University of Brighton. He obtained his degree in Pharmaceutical and Chemical Sciences in 2002 and his $\mathrm{PhD}$ degree in Bioengineering at Imperial College London in 2005. Following this he obtained an overseas life sciences fellowship to develop electrochemical sensors to study neurotransmitters, where he spent time at Michigan State

University and the University of Calgary. In 2010 he became a full-time member of the teaching faculty delivering analytical chemistry to undergraduate and postgraduate students. His research is focused on the development of novel electrochemical approaches for monitoring key signalling molecules. He has also an interest in development of novel blended learning approaches for the delivery of analytical chemistry. 